\title{
NOTICIAS
}

\section{El proyecto del genoma humano, un hito de la ciencia}

La secuencia del genoma humano ha capturado la imaginación de los científicos en una forma en que la ciencia y la tecnología no lo hacían desde que el hombre pisó y caminó en la luna y, de la misma forma, alteran nuestra perspectiva sobre lo que significa el ser humano.

El proyecto da inicio en 1990, como una colaboración internacional coordinada por el Departamento de Energía y los Institutos Nacionales de Salud de los Estados Unidos de América (EUA), y se planea con duración de 15 años. Sin embargo, los adelantos científicos y tecnológicos recientes han acelerado su desarrollo y se espera su conclusión para el año 2003. Las metas del proyecto son:

- Identificar todos los genes en el ADN que aproximadamente son 100000

- Determinar las secuencias de los 3.3 billones de bases nitrogenadas de las que está compuesto el ADN

- Guardar toda la información en bases de datos

- Desarrollar sistemas para el análisis de datos, $\mathrm{y}$

- Delinear los aspectos éticos, legales y sociales que se generen del proyecto.
En diciembre de 1999, investigadores de EUA, Inglaterra, Canadá, Suecia y Japón publicaron en Nature la secuencia de los 33.5 millones de bases nitrogenadas que componen el ADN del primero de los 23 cromosomas humanos secuenciado, el 22. El análisis de la secuencia ha revelado que este cromosoma contiene información sobre el funcionamiento del sistema inmune, sobre los mecanismos que participan en las enfermedades congénitas cardiovasculares, la esquizofrenia, retardo mental y algunos cánceres como la leucemia.

Pocos meses después, en mayo de 2000 y en la misma revista, investigadores de EUA, Alemania, Francia, Suiza y Japón demuestran que el ADN del cromosoma 21 está compuesto por 33 millones de bases y su secuencia revela genes relacionados con enfermedades específicas como el síndrome de Alzheimer y algunos cánceres. Esta secuencia también representa una herramienta invaluable para el estudio del síndrome de Down causado por la presencia de tres (en lugar de dos) copias del cromosoma 21 en células somáticas.

Casi en forma paralela, el Departamento de Energía estadunidense anunció la decodificación parcial de los cromosomas 5, 16 y 19 que contienen entre 10 y 15000 genes incluyendo aquellos asociados con enfermedades como disfunción renal, cáncer de próstata y colon, hi- pertensión, diabetes y aterosclerosis. La secuencia definitiva de ellos se concluirá en poco tiempo.

Los resultados del proyecto del genoma humano se encuentran disponibles por medio de bases de datos como el GenBank (www.ncbi. nlm.nih.gov/genome/seq) sin necesidad de permisos o patentes para todos los científicos, lo que favorece el avance en el diagnóstico y tratamiento de diversas enfermedades.

La tecnología y conocimientos generados por este proyecto han impactado en forma importante el desarrollo de diversas ciencias. El potencial para el desarrollo comercial de investigación genética ofrece muchas oportunidades para la industria y se esperan ventas enormes de productos y tecnologías basados en el ADN en la industria biotecnológica en el futuro cercano.

Algunas de las áreas involucradas en el campo de la salud pública que serán beneficiadas por los avances generados de este proyecto incluyen:

- Medicina molecular. Estará caracterizada por una disminución en el tratamiento de los síntomas y por un mayor esclarecimiento de las causas fundamentales de la enfermedad. Las pruebas de diagnóstico rápidas y con mayor especificidad permitirán tratamientos tempranos y disminución de 
enfermedades. Los investigadores contarán también con agentes terapéuticos nuevos, técnicas de inmunoterapia y, posiblemente, con la capacidad de remplazar genes defectuosos mediante terapia génica

- Genética microbiana. La información generada de la caracterización de los genomas de diversos microrganismos, principalmente bacterias, que se lleva a cabo como un programa colateral del proyecto del genoma humano, permitirá el desarrollo de biotecnologías que empleen sistemas microbianos productores de energía, como los sistemas fotosintéticos, que funcionen en ambientes extremos y que puedan metabolizar desechos en materia renovable para disminuir así contaminantes ambientales que dañan la salud. En forma más directa, el conocimiento de los genes de bacterias patógenas permitirá el diseño de nuevos agentes antimicrobianos que actúen de tal forma que no se dañe la flora normal de la cual dependemos para nuestra subsistencia y en la producción de nuevas vacunas

- Análisis de riesgos. El conocimiento del genoma humano tendrá un impacto enorme para evaluar los riesgos de los individuos expuestos a diferentes tóxicos, agentes mutagénicos, radiaciones y mutaciones hereditarias

- Evolución y antropología. El estudio de la evolución humana se verá beneficiada al poder comparar nuestros genes con los de otros organismos, así como la migración de diferentes grupos de población basados en marcadores genéticos femeninos o en el análisis del cromosoma $Y$ en el sexo masculino
- Medicina forense. En un futuro cercano se podrán caracterizar grandes fragmentos de ADN que permitan la identificación precisa de cualquier individuo. Se avanzará en la elucidación de crímenes, en el establecimiento de paternidad y otras relaciones familiares y en el fortalecimiento de los programas de trasplantes de órganos al precisar la compatibilidad entre donadores $\mathrm{y}$ receptores, $\mathrm{y}$

- Nutrición. Finalmente, el conocimiento de los genomas tanto de animales como de plantas que empleamos para nuestra alimentación permitirá crear organismos resistentes a las plagas y enfermedades, reducir el costo en la agricultura y ganadería para producir alimentos libres de plaguicidas y antimicrobianos.

El pasado 26 de junio, científicos de Gran Bretaña, Estados Unidos, Japón, Alemania, China y Francia divulgaron el mapa del $97 \%$ del genoma humano y la secuencia exacta de $85 \%$ de las bases de la molécula del $\mathrm{ADN}$ en lo que es considerado por la comunidad científica como el primer gran triunfo tecnológico del siglo XXI. En Japón, el director del Proyecto de la Agencia de Ciencias de ese país, Yoshiyuki Sakaki, fue el primero en revelar al mundo el resultado de las investigaciones en las que se logró identificar unos 38 mil genes, formados a su vez por pares de bases nucleotídicas, cuyo número se sitúa entre 3 mil y 3 mil 500 millones, y que contienen la información genética que define al individuo, todas sus características internas y externas, así como su tendencia congénita a desarrollar ciertas enfermedades. Esta meta, que se había fijado para el año 2003, se alcanzó tres años antes por lo que la decodificación completa del genoma se estima en muy poco tiem- po. Los investigadores del Proyecto del Genoma Humano propusieron crear un parlamento mundial para establecer criterios éticos universales sobre las potenciales aplicaciones de este descubrimiento, dado que actualmente no existen leyes en ningún país sobre este concepto.

¡Felicitaciones a los investigadores del Proyecto del Genoma Humano!

\section{Gabriela Echániz A vilés, Jefa del D epartamento de Diagnóstico Epidemiológico,Centro de Investigación sobre Enfermedades Infecciosas, \\ Instituto N acional de Salud Pública, México.}

\section{A cerca de condones y cinturones de seguridad: una desafort unada comparación}

Recientemente, ha aparecido un artículo, de los denominados de opinión (Viewpoint), de John Richens, John Imrie y Andrew Copas, Condoms and seat belts: The parallels and the lessons (Lancet 2000; 355: 400-403), que trata de establecer paralelismos entre dos intervenciones utilizadas para prevenir problemas de salud pública: los accidentes de tránsito mediante el uso del cinturón de seguridad y el síndrome de inmunodeficiencia adquirida por medio del uso del condón.

Los autores basan su análisis en el paralelismo de que ambas medidas se utilizan en el cuerpo humano para salvar vidas; sin embargo, dicho paralelismo no existe, pues mientras que el cinturón es una medida de prevención secundaria (no previene el accidente, sino una vez que éste ocurre limita el daño en términos de consecuencias graves), el condón es una medida de prevención primaria dirigida a evitar la infección por el virus de la inmunodeficiencia humana. 
Además, mientras que el uso del cinturón protege sólo al que lo utiliza y a nadie más, el condón tiene el doble beneficio, tanto para el que lo utiliza como para su pareja. Lo anterior significa que mientras que el uso del condón requiere del acuerdo entre dos personas, el uso del cinturón de seguridad, no.

Es un artículo que plantea lo que $R$. Veatch ${ }^{1,2}$ describe como el modelo psicológico en el análisis de los comportamientos de la población frente a los riesgos, e introduce el concepto de risk compensation: que se refiere a cuando un nuevo dispositivo de seguridad, al ser introducido al mercado, produce una percepción de permisibilidad al riesgo, entonces la búsqueda de toma de riesgo se vuelve más atractiva y genera un incremento compensatorio en esa toma de riesgo. En el caso de los accidentes de tráfico produce un incremento en la velocidad. Plantear el efecto del cinturón de seguridad a nivel poblacional por medio de cambios en las tasas de mortalidad por accidentes de tráfico es incorrecto, pues esto significa partir de lo que en epidemiología se denomina modelo unicausal, en el que, ante la eliminación de una causa condicionante, se obtiene una modificación del efecto, que en este caso es el daño más extremo, la muerte. Lo anterior en el caso de los accidentes de tráfico sería olvidarse del resto de los actores que participan en este fenómeno, como son los ocupantes de los vehículos, los motociclistas, ciclistas y los peatones, así como de la presencia de otros factores de riesgo, como son la velocidad, edad, ingesta de alcohol, tipo de camino, ámbito de ocurrencia, etcétera. Además, las estadísticas que utilizan para sustentar su afirmación son, las más recientes, de hace 22 años, cuando los vehículos de motor sólo contaban con cinturón para el conductor, mientras que en la ctualidad esta medida se ha generalizado para todos los ocupantes del vehículo.

En el caso del condón esto se traduciría en que, ante la sensación de seguridad que produce su uso, genera un aumento en el número de contactos sexuales entre jóvenes o en población de alto riesgo, a lo que además se suma el que aproximadamente $10 \%$ de los condones presentan fallas de fabricación. El ejemplo que utiliza considero que tampoco es el más adecuado.

Esta comparación tiene otras implicaciones en términos de denominadores, ya que no es lo mismo medir el porcentaje de uso de cinturón en una comunidad que el porcentaje de uso de condón.

Estoy en desacuerdo en la conclusión de que el cinturón no ha aportado los beneficios que de él se esperaban, ya que existen $\mathrm{N}$ trabajos que prueban lo contrario. ${ }^{3}$
En la única medida en que serían comparables ambos eventos es que, efectivamente, la evaluación de ambos tipos de intervención debe ser planeada tomando en consideración las características de la población y en la que los aspectos de comportamiento hacia la toma o no de riesgos en el uso o no de uno $u$ otro dispositivo está permeada, más que por la atracción hacia el peligro, por las características culturales de la población. Llama la atención lo que menciona al final del artículo en donde dice que habría que preguntarnos por qué la promoción en el uso de condón aparentemente no ha tenido mucho efecto en la mayoría de los países en desarrollo (pero no aclara de donde proviene esta afirmación).

Martha C. Hijar, InvestigadorTitular B

Centro de Investigación en Sistemas de Salud Instituto $\mathrm{N}$ acional de Salud Pública, México.

\section{REFerEn Cias}

1. LaurenceW W.Acceptable risk. LosAltos (C A): Kaufman Inc. Ed., 1976:75-101.

2. Fischhoff $B$, Slovie $P$, Lichtenstein S. W eighing the risks. Environment 1979;21(4):17-20, 32-38.

3. Graham J. Injuries from traffic crashes: Meeting the challenge. Annu Rev Public Health 1993;14: 515-543. 